\title{
Issues and Challenges of Ghana School Feeding Programme in the KEEA Municipality Ghana
}

\author{
Clara Akuamoah-Boateng (Mrs.) \\ College of Distance Education, \\ University of Cape Coast, Ghana. \\ Josephine Sam-Tagoe (Prof.) \\ College of Distance Education, \\ University of Cape Coast, Ghana.
}

\begin{abstract}
Ghana as a developing country embraces formal education is pivotal in its development agenda. Furtherance to this agenda, Ghana was among the first ten developing countries in Sub-Saharan Africa to implement a School Feeding Programme using the NEPAD model. The long term goal of the School Feeding Programme in Ghana, is to contribute to the achievement of the Millennium Development goals (MDGs) 1\&2 which aim at eradicating extreme poverty and hunger and to achieve universal primary education. Specifically, the school feeding programme in Ghana seeks to motivate parents to send their wards to school, improve school attendance, participation and retention and to improve the nutritional status of primary children in vulnerable communities in the country. Empirical research studies available suggest that the programme has witness some successes since its inception 2005, in areas such as primary school enrollment, participation and retention. However, it appears the programme is bedeviled with some of implementation challenges that pose serious threat to achieving the lofty benefits enshrined in the long term goals and sustainability of the programme. This paper sought to examine the issues and challenges of the GSFP in the KEEA Municipality of the Central Region of Ghana and offer some suggestions and recommendations for the improvement and sustainability of the programme.
\end{abstract}

Key Words: School feeding programme, issues, challenges, enrollment, retention, participation.

\section{INTRODUCTION}

School feeding programme is a social safety net for primary school children as part of the national development agenda in many developing countries including Ghana. It provides incentives for poor families to send their wards to school, to encourage participation and retention in school as well as improving the nutritional health status of beneficiary children. The Ghana School feeding programme (GSFP) was introduced under the initiative of the African Agricultural Development Pillar 3 which seeks to improve food security in developing countries

\section{METHODS}

Data was collected from the internet, research articles and policy documents on the Ghana School Feeding programme and School Feeding Programmes of other countries.

\section{THE CONCEPT AND ORIGIN OF SCHOOL FEEDING PROGRAMMES}

School feeding is simply the provision of school meals to children during school periods. School feeding intervention programmes differ from country to country depending on the mode of provision, objectives and long term goals for its implementation differ from country. Oyefade 
(2014), mentions that different countries have one or a combination of two feeding programme modalities in place for various objectives. However, school feeding programmes can be categorized into two: in-school meals and take- home rations where beneficiary pupils' families are supplied with food. These broad categories could further be sub- categorized into: programmes that provides meals and programmes that provides high-energy snacks to generate greater impacts on school enrollment, retention rates and reduce gender inequalities and other social gaps (Akanbi, 2013). There are indications of a significant swing in thinking about school feeding programmes in many countries, and many elements of the strategy are being promoted keenly under the rubric of "home grown school feeding" Historically, inschool meals provision have been the most popular model of school feeding interventions in many countries (Uduku, (2011).

The emergence of school feeding programmes according to Tomlinson (2007) could be traced back to the 1930s in the United Kingdom and the United States of America with a focus on improving the nutritional status of school children. In 1900, Netherlands become the first country to move the programme to a new level of incorporating school meals into a national legislature. By the 1930s, the United Kingdom and the United States of America had instituted school feeding programmes as part of their national programmes. Taylor\&Ogbogu, (2016). A further account by Taylor et al, (2016), indicates that school feeding initiatives have been in existence since the late 1700's and originated as projects of donors agencies in Europe. The United States of America began the practice of initiating school feeding programmes in Austria as an act of international aid which focused on combating the severe malnutrition of children in the 1940s after the Second World War. Since then, school feeding programmes have become a key element of food assistance, emergency relief and development programmes in many developing countries.

The world Food Programme (2009), explains school feeding needs "as the global number of undernourished, primary school going-age children enrolled in primary school" (p.5). Based on this description, WFP (2009) argues that as many as 66 million primary school children in 94 developing countries are under-nourished. An estimated amount of US\$3.2 billion is needed every year to provide meals for these primary school children; and school feeding programmes had reached 22.6 million school children in 68 countries.

Notwithstanding this development, FAO,(2005) reports that as many as 66 million school- age children attend school daily without meals in most developing countries of the world especially in Sub-Saharan African. Most parents and care givers in these countries, especially in the rural communities are unable to provide the basic meals of the day to their wards in school due to poverty. The report further revealed that the estimated number of primary school drop outs in sub- Saharan Africa keep rising over the past two decades. Efforts to reduce the number of primary school drop outs which stands around 61 million have been slow and stagnant since 2008. A combined programme of teaching and feeding hungry primary school children have been introduced in many of these countries to improve primary school enrollment, participation, retention and to improve the nutritional health status of the school children.

The WFP, (2013) and other development partners such as UNICEF, DFID and FAO argue that there has been an increase in demand for, interest in and coverage of school feeding programmes in many countries. This varies from high, middle and low incomes countries. In high income countries generally, in-school feeding covers all primary school children. Whereas in middle and low income countries, school feeding programmes are provided only to some needy primary school children from selected communities based on vulnerability factors. Empirical research studies suggest that coverage of the programme continues to be low in low 
income countries where the need is greatest in terms of hunger, poverty and other poor social indicators.

\section{BACKGROUND OF THE GHANA SCHOOL FEEDING PROGRAMME}

Ghana was among the first ten developing countries in Sub- Saharan Africa to implement a school feeding programme modelled with the New Partnership for African Development (NEPAD) guidelines. FAO, (2005). The Ghana School Feeding Programme seeks to use education as a vehicle for advancing and implementing development policies and programmes. The programme strives to achieve its long time objectives of boosting domestic food production; increase primary school enrollment, participation and retention. The Ghana government with support from the Dutch Government implemented the School Feeding programme in September, 2005 with ten pilot schools in each region across Ghana. Available statistics on the programme, show a steady increase in the number of beneficiaries of the programme over the years since its inception.

As a way to improve the nutritional status of primary school children among others, the GSFP employs the in-school model of the school feeding programme to provide primary school children with one hot daily meal, prepared from local foods. Beneficiary school children are provided with daily lunch to minimize the need for them to leave the school to find food, lessen their hunger, boost their attention span during lesson delivery, facilitate their learning and improve their nutritional health status in the long term. These meals are usually prepared in the school environments by hired caterers. The programme targets children are drawn from public kindergartens and primary schools in the vulnerable communities across the country (GSFP Annual Operating Plan, 2011)

As the programme seeks to provide with one hot nutritious meal during the school day using locally produced foodstuffs, the programme insist on buying locally grown foodstuffs from local farmers (Abu-Bakr, 2008, p.4; ECASARD/ARD/SNV Ghana, 2009). The programme therefore is expected to reduce the rate of malnutrition in beneficiary children, while providing the local farmers the opportunity to sell their produce to caterers of beneficiary schools. By August, 2006, the number of beneficiary schools had increased to 200 covering about 69,000 primary school children in 138 districts in the country (ECASARD/SNV Ghana, 2009; Afoakwa, n.d). Currently, the programme provides meals to about 2.1 million primary school children totaling $47.60 \%$ of primary school children in the country. This was announced by the Minister of Finance, Ken Ofori Atta in the 2018 mid-year budget when he mentioned "We have increased the School Feeding Programme beneficiaries from 1.6 million to 2.1 and also increased the amount spent on each child by 25 percent"(m.peacefmoline.com/pages/local/news /2018/357978php).

\section{ADMINISTRATION AND ISSUES OF THE SCHOOL FEEDING PROGRAMME IN KEEA MUNICIPALITY}

The concept of school feeding appears to be simple but it is a complex intervention that requires careful planning and adequate management for the sustainability of the programme. Komenda-Edina-Eguafo- Abrem (KEEA) municipality has been a beneficiary of the school feeding programme intervention since its introduction in 2005. Although some empirical research studies exist assessing the prospects, successes and challenges of the programme nationally, it appears no empirical research study has been conducted to examine the issues and challenges of the programme in the KEEA municipality. This study therefore fills this research fills this research gap, offer suggestions, make recommendations for the improvement and the sustainability of the GSFP programme in the municipality. 
The KEEA municipality is one of the six Municipal Assemblies in the Central Region of Ghana. The Municipality is made up of four traditional areas put together to constitute a political administrative entity. The municipality was carved out of the then Cape Coast Council in 1978 with Elmina as the Capital town, which was the first point of contact with the early Europeans to Ghana. Elmina town therefore had witnessed a lot of western civilization and influence as well as other economic activities over the centuries. Education undoubtedly is one the fundamental pre-requisite tools towards socio-economic development. The progress of any society depends on the affordability, accessibility, quality and capacity of the educational system. Education provides the capacities tools and means for future employment and local development. In furtherance against this back drop, the KEEA municipality embraced the GSFP at the initial stages when the programme was introduced in 2005. The programme

Figure 1: A map of the Central Region of Ghana, showing the KEEA Municipality.

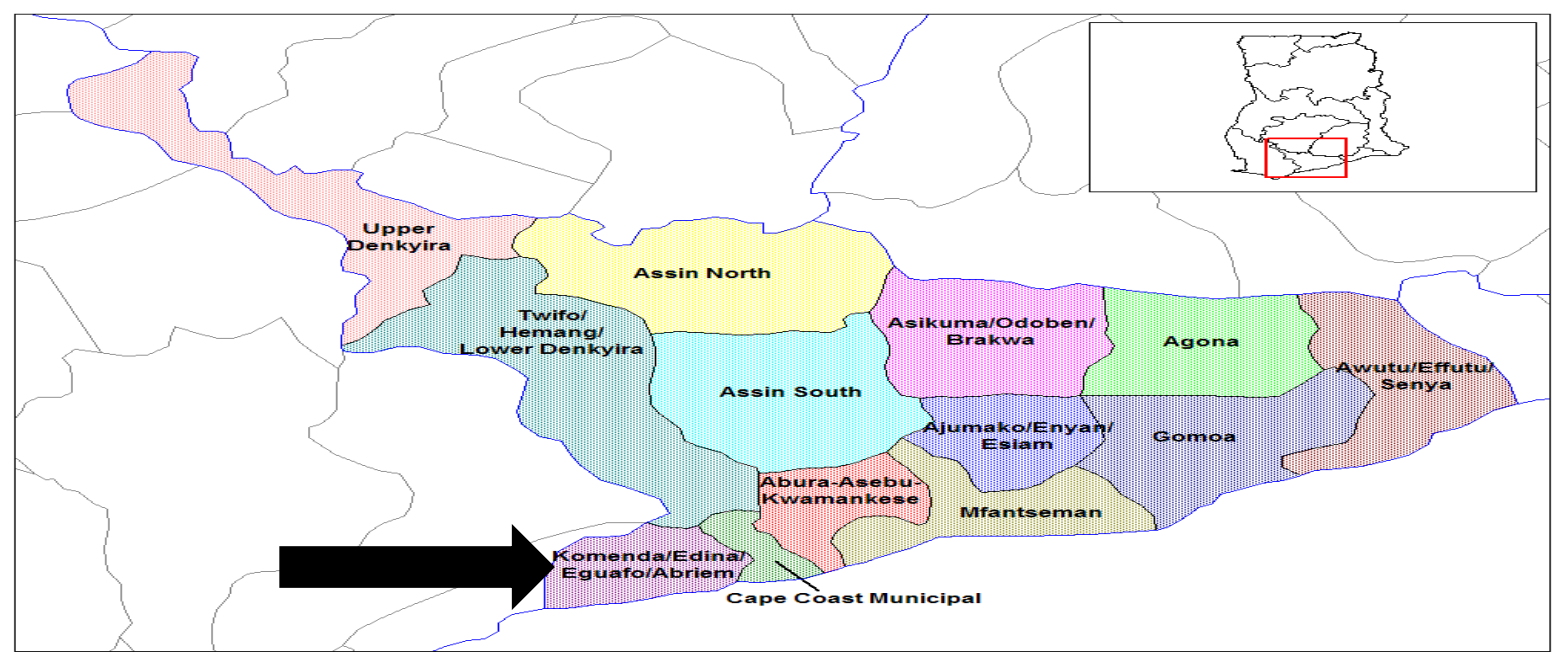

INSTITUTIONAL ARRANGEMENTS OF THE GHANA SCHOOL FEEDING PROGRAMME

The initial major funding partners of the GSFP programme nationally, were the Dutch Government, the World Food Programme, and the Government of Ghana contributing 17\%, $5 \%$, and $78 \%$ respectively of the annual cost based on GSFP annual budget (Buhl, 2012). The technical support partners of the GSFP initially included: United States Agency for International Development (USAID), the Netherlands Development Organization (SNV), Royal Netherlands Embassy, World Food Programme (WFP), Food and Agriculture.

Organisation (FA0), Catholic Relief Services (CRS), and the Adventist Development and Relief Agency (ADRA). The Ministry of Local Government and Rural Development of Ghana, has the overall oversight responsibility (Buhl, 2013). However, the Netherlands Government ceased funding the programme in 2011.

For efficient management of the programme, the government of Ghana constituted governance structures at the national, regional, municipal/ district and community levels. At the national level, a constituted ministerial committee made up of the five ministries; health, agriculture, education, women and children affairs, local government was initially established to manage the programme. Unfortunately, all the ministries showed interest in the programme and the end results was power struggle among those ministries in the attempt to manage the programme at the national level. To foster the smooth implementation of the programme, all the ministries were dropped except the Ministry of Local Government and Rural Development which was given the oversight responsibility of the management of the programme (Morgan \& Sonnino, 2008). 
From the national level to the regions are regional coordinators and monitors who are appointed and supported by the National GSFP

Secretariat to coordinate, supervise and monitor the programme at the municipal and district levels. The regional coordinators also establish committees and serve as a link with authorities in the municipal and the district levels. (Kedze, 2013)

The municipal and the district levels actors are crucial in implementing the GSFP Programme. At the KEEA municipality, the Municipal Assembly is responsible for setting up the Municipal Implementation Committee (MIC) under the chairmanship of the Municipal Chief Executive (MDE). The major responsibilities of the municipal implementation committee (MIC) are to manage the programme in the municipality, opening bank accounts where funds are deposited, and to see to the smooth running of the programme in the municipality (Morgan \& Sonnino, 2008); Sulemana et al., 2013).

The Municipal Implementation Committee (MIC) exercises direct oversight of the implementation of the programme in all beneficiary schools in the municipality. In addition, the (MIC) oversees to the implementation and management of all other components of the programme at the municipal level. The MIC is also responsible for the provision of specified infrastructure and to mobilize community support to provide inputs for the beneficiary schools. Additionally, the committee is responsible for distributing funds to the School Implementation Committee (SIC), holding them accountable for the use of the funds. The Municipal Chief Executive, a Government Appointee, Municipal Directors of Education, Agriculture and Health, Municipal Budget Officer constitute the (MIC). (Kedze, 2013).

The Municipal Chief Executive also sees to the setting up of a School Implementation Committee (SIC) with the local school head of the beneficiary school as the chairperson. The responsibilities of the (SIC) is to hire cooks for the school, plan the menu, procure food commodities from local farmers and to supervise the preparation of meals and feeding of beneficiary children.

At the local level, is the School Implementation Committee (SIC). The (SIC) is a structure at the community or local level within in the beneficiary school location that over sees to the day- today activities of the GSFP programme. The (SIC) is basically made up of local members from the school community. The members of the local SIC includes head teachers of beneficiary schools, two Parent Teacher Association (PTA) members based on gender (male and female), and two members from the School Management Committee (SMC). (male and female), a traditional/local chief or his representative, one religious leader, one Assembly member, two males two females opinion leaders in the community, and the senior prefects of the schools (male and female) (Sulemana et al., 2013; Morgan \& Sonnino, 2008). It is at this level that the principle of community participation is expected to be visible. Acknowledging this, the government implementation document of the GSFP strongly expects the establishment of a well-designed school level SIC that incorporations all actors of the GSFP at the community (HGSF TAP, 2011: 32)

\section{ISSUES OF THE SCHOOL FEEDING PROGRAMME IN THE KEEA MUNICIPALITY}

The School Feeding Programme in the KEEA Municipality has some laudable educational, social and economic prospects for the beneficiaries in the municipality and the country as a whole if it is properly managed. It was estimated that about $80 \%$ of the school feeding programme expenditure would be used to purchase "home grown foodstuffs" as a measure to reducing post-harvest loses of foodstuffs in the beneficiary school communities of the GSFP. 
Naturally, the KEEA Municipality abounds in lot of the local food commodities from the sea (Edina and Komenda) and from the farms in the hinterlands (Eguafo and Abrem). The majority of the inhabitants are mostly fishermen and farmers. The main economic activities of the municipality therefore include fishing in the coastal, lakes areas and farming in the hinterlands. The majority of the rural folks in the municipality are peasant farmers who cultivate maize, cassava, pepper, okra, watermelon pepper among other Ghanaian foodstuffs. There are however some large commercial farms which produce pineapple, watermelon, pawpaw, mangoes, pepper, oranges and coconut for local consumption and for exports to the neighbouring countries. These type of farmers usually employ local farm hands. Poultry breeding is another form of economic activity in the municipality. The urban and the Periurban communities also engage in varied economic activities such as being artisans, petty trading, handicraft, civil servants and industrial workers. Cassava dough production and gari making are some of the food processing activities. The Broniyebimah salt industry is also operating in the free zone area of the municipality. The structure of the local economy is predominately agriculture, followed by service and industry respectively.

Against this background, the KEEA Municipality with its natural resources, serves as a "fertile ground" to harness the lofty goals enshrined in the School Feeding Programme especially in using "home grown" foodstuffs to reduce post-harvest loses. Foods commodities that are normally used for meal preparation in a typical Ghanaian home such as fish, poultry, meat, eggs, beans, gari, cassava, variety of fruits and vegetables and even salt are available in the municipality. Irrespective of this advantage in the KEEA Municipality, some available research studies on the GSFP suggest that most of the school feeding programmes in the country appear not to be using the food commodities grown by the local farmers in the beneficiary communities for the preparation of school meals in the schools as initially planned in the programme implementation document. This situation is not very different in the KEEA municipality in terms of the purchasing of local food products from local farmers. The situation clearly undermines one major objective of the GSFP programme of reducing post-Harvest losses.

In her work, De Hauwere (2008) (n.d: 353) observed that despite the programme objective to use home grown produce, effectively and successfully linking the GSFP to the local agriculture economy of Ghana has been a major hurdle. She asserts that only a limited number of food commodities for the programme are purchased from the local farmers in the beneficiary communities. The caterer model of the programme is unable to link small scale farmers with caterers of the beneficiary schools for food supply, thus, it is important to establish links between the local farmers that the programme aims to support and the reliable demand for food commodities needed by the programme.

In another development, a research study carried out specifically on GSFP in the Natrona community of the KEEA municipality by Lynch, (2013) supports the claim made by De Hauwere (2008). She also recommended that foods commodities for the GSFP in the KEEA municipality should be purchased from the local farmers in the communities in which beneficiary schools are located as planned in the implementation document. These revelations from the two research studies go to suggest that there is an urgent need to address this issue with respect to encouraging local food production and purchasing within the beneficiaries' school communities. If this is done, it will go a long way to help facilitate local economic development. Although some strategies have been put in place such as the formation of farmbased organizations to address the challenge, little progress had been achieved (HGSF TAP, 2011:25). 
The GSFP through private caterers, awards contracts caterers to procure, prepare and serve food to children in beneficiary schools(caterer model) As a parameter for the procurement of food under the programme, it is expected that foods procured for the programme must be locally grown food commodities produced by local farmers of beneficiary communities the municipality. Furthermore, the caterers are expected to purchase foods within the community levels within ones district, municipality or within regional markets or at worst, within Ghana, but, the caterers are not restricted and are able to procure on a competitive basis without commitment to purchasing from small-scale farmers. The preparation and distribution processes of food for the GSFP is the duty of the caterer and the processes are unique in each case. In general, caterers prepare food on site, even though in some instances the caterers prepare food in distant kitchens and deliver the prepared meals to the school to be served to the beneficiary children (HGSF TAP, 2011;46).

It is however, without doubt that the role of the caterer in the smooth running of the GSFP at the community level is very important; caterers are the link between the local farmers and the programme. In doing so, the caterer is to ensure maximum hygiene (personal, food, kitchen and food service area) in the preparation of meals. The caterer is to collaborate with School Implementation Committee (SIC) to prepare meals with a locally based menu for the beneficiaries, ensuring that meals prepared are nutritionally balanced and adequate. To perform these duties, the caterer must ensure utmost cooperation with school authorities and the SIC. Kedze, (2013).

The most obvious expected long term goal of the GSFP is the increase in enrolment of beneficiary children, participation and retention. Despite these expectations, it is ironic that as this long term goals of the programme appear to be achievable, further strategies to protect the quality of the beneficiaries' education in the KEEA municipality have been critically low. Lynch, (2013), in her research study on the GSFP in Ntranoa community of the KEEA Municipality attest to this fact. She indicated in her study that there is enough evidence to suggest that stakeholders of education in the Ntranoa community is of the believe that the GSFP is doing well in terms of aiding attendance, participation and retention levels of children in schools.

Notwithstanding this perceived advantage, the reality of the situation on the ground in the KEEA Municipality is that enrolment, participation and retention in beneficiary schools of the GSFP have increased without the corresponding expansion of educational resources to meet the present needs of the schools in the Municipality. For instance, increases in school enrolments obviously demand the relative increase in the number of teachers, other teaching materials and logistics. These educational resources appear not to be forthcoming coming in the beneficiary schools in the Municipality.

De Hauwere (2008) (n.d:351) corroborates this assertion in her research study of the GSFP noting "the only positive development in the GSFP is the increase in enrolment of beneficiary schools. Unfortunately, this was not accompanied by additional steps to safeguard the quality of education in terms of a proportional increase in school infrastructure and other logistical support" The author further asserts that in the quest to scale up enrolment rates, the GSFP compromised in targeting beneficiaries for the programme at the poor, this is evidenced in the first phase of the programme.

Citing the World Bank (2000a), Tomlinson (2007 p.11) posts "it has also been argued that school feeding programmes, only improves learning when the food is accompanied by other inputs related to the teaching quality". The availability of corresponding educational resources in the GFSP with proper management will greatly influence the quality of teaching and learning 
in beneficiary schools in the Municipality. As it is evident that schools without adequate teachers, teaching and learning materials will not be able to do an effective job (Ankomah, Koomson. Bosu \& Oduro, 2005). The GSFP seeks to contribute to poverty reduction, thus targeting primary school children in vulnerable communities across the country yet, there appears to be some implementation challenges to contradict the purpose of the programme. Community support and ownership for the programme appear to be non-existent in the municipality.

The managerial set up for the GSFP in the KEEA municipality appears not to be working appropriately. For instance, some head teachers have been left with the sole responsibility of making decisions to make sure that beneficiaries are fed as other members of the local committee fail to participate in the day- to- day activities of the programme. In such cases, decision making on the programme are subsequently undertaken by the head teacher and the caterer. This practice militate against the recognition of the need to strengthen community mobilization and involvement in the programme. It is expected that the day- to -day activities of the GSFP will carried out through the collaboration of all actors of the programme as spelt out in the implementation document of the GSFP (HGFS TAP, 2011:32).

There appears to be some form of apathy within the local level committees of the GSFP in the KEEA municipality. It was however not very clear whether the school level committee members need some form of motivation in order to participate fully in such a beneficial programme in their own communities. The situation if it continues, will not help to sustain the programme since the local people are key stakeholders for the smooth implementation, sustainability and ownership of the programme in the long term.

School heads and teachers are also very vital in the GSFP. School heads are responsible for the daily supervision of the caterers in their schools. They monitor the caterers to ensure that they perform their roles as stipulated. The school heads prepares reports on the activities of the programme in the schools and present to the Municipal Assembly. Schools heads liaise with other actors of the programme to develop a local-based menu. Teachers on the hand are charged with the responsibility of ensuring that the children do not perform any duties associated with the programme during school hours, only eat the food and attend classes. The teachers prepare reports on the programme to the Municipal Desk Officer of GSFP at the Municipal Education Directorate. The selection of a pupil representative to the School Implementation Committee rests on the teachers. The pupil representative is make contributions and suggestions to the (SIC) in the School. Also the teachers in collaboration with the school head are to enhance cooperation with the caterer (Kedze, 2013). This institutional arrangements seem not to be working effectively in the beneficiary schools in the KEEA municipality as observed by Lynch, (2013).

Buhl, (2012) asserts that an estimation of over three quarters of young children and about half of women of child bearing age suffer from anemia in most developing countries south of the Sahara. It has also been established that children who are malnourished do not go to school early and tend to complete at fewer years than class mates who are better nourished. (Buhl, 2012). Against this background, the menu for the GSFP in the KEEA municipality is based on national nutrition guidelines which are adapted to suit local nutritional needs of beneficiaries and availability of local foodstuffs. It is envisaged that all stakeholders of the programme in the municipality will be committed in ensuring that beneficiaries' school meals prepared and served are varied and nutritious, at the barest minimum cost using local grown food commodities. 
The typical staples foods of most Ghanaians including the KEEA Municipality are mostly the starchy roots (cassava, yam, cocoyam and plantain), fruits, and cereals (rice maize and millet). These staples are about three quarters of foods in-take energy for most Ghanaian families. "Malnutrition, stunting growth, vitamins and mineral deficiencies and other dietary related diseases," among others are common problems of children in the municipality. Buhl, (2013) establishes the following childhood nutritional deficiencies in Ghana:

- $14 \%$ of children under five suffer from moderate to severe underweight

- $9 \%$ of children under five suffer from moderate to severe wasting

- $28 \%$ of children under five suffer from moderate to severe stunting

- Only $32 \%$ of households consume iodized salt

- Only $24 \%$ of children under five receive vitamin A supplementation.

These indications have a serious bearing on the long term goal of the school feeding programme in Ghana.

It is therefore not surprising that the major objectives of the programme are to (a) " reduce malnutrition in school going children through diet supplementation via a complete and adequate meals in terms of calories and micronutrients, and (b) to expand local demand for food produce and stimulate production of food by smallholder farms" (Sulemana, et al., 2013; Oduro-Ofori \& Adwoa-Yeboah, 2014).

The increase in teaching staff and workload distribution in beneficiary schools in the KEEA Municipal is an issues worthy considering if the GSFP is to become successful in the municipality. To reduce the extra burden on teachers in beneficiary schools, school authorities had requested for more teachers to be brought in to help ease the burden. As a short term measure, some schools have two teachers in one class. Unfortunately, there are indications to suggest that this arrangement is not making much difference to lessen the workload of the teachers in the beneficiary schools in the municipality. The additional teachers are normally subject teachers and when it is time for them to teach their assigned subjects, they still teach the same number of children in a class singlehandedly.

Another effort made by the authorities of the GSFP beneficiary schools in the municipality to lessen the burden of the teachers load is that some schools accept trainee teachers who come in yearly on teaching practices, and depending the ability of the school to accommodate them, a large number of these trainee teachers are brought to help to offload some of the teachers working loads as an interim measure. Kedze, (2013) believes this arrangement where teachers in beneficiary schools are overburdened with work load really puts a very heavy toll on the school authorities particularly the school heads and teachers. Kedze further argues that work that should have been done by two teachers is carried out by just one teacher. She questions how the teachers in such a situation could give off their best and lamented "this trend is making the teachers' work more difficult". Ankomah et al (2005 p.8) on the other hand points out that researchers have argued that measured pupil-teacher ratios are sound approximations of actual class size, particularly, at the primary school level, stressing that the quality of education is much higher when the pupil-teacher ratio is much lower and this improves student's achievement.

Nonetheless the role of beneficiaries' parents cannot be ruled out in easing the burden of teachers. Irrespective of the increase in enrolment and other infrastructural challenges mitigating against effective teaching and learning in the schools, parents in the municipality appear to be doing very little on their part to collaborate the teaching efforts of the teachers in enhancing the learning capabilities of their wards. For instance, parents fail to supervise their 
wards homework and are unable to provide the basic needs that enable the children to participate fully in school activities. Very many parents do not show concern in the education of their wards. Parents could do better by showing interest in the education of their wards through occasional school visits, to have a feel of how their wards are faring in school. Kedze, (2013) reveals that the academic performance of pupils whose parents supervise their studies was much better than pupils who had no parental supervision (Kedze, 2013, p.31).

The burden of funding the GFSP, rests heavily on the government of Ghana; government funds for the programme have been inconsistent, resulting in delays in the release of feeding grants to the municipality (GSFP AOP, 2011P.12). A delay in the release of feeding grants subsequently affects beneficiary children. This implies that caterers may not be able to access funds to procure, prepare and serve meals to beneficiary children. On the other hand, even if the caterer is able to pre- finance the feeding of the pupils, the quantity and quality of food served will be compromised. There is the likelihood that food served will not be nutritious and adequate.

This problem appears to be a national issue of the programme and the KEEA Municipality has its share of the effect of the problem. If the GSFP is designed to provide beneficiaries with one "hot nutritious meal" each day of school to enhance enrolment, academic work and retention and the programme appears to be bedeviled with such major problem, then the lofty goals enshrined in the programme are not likely to be achieved. Apparently, the delay in the payment of the caterers has a direct impact on the school children as the quantity and quality of meals served will be taken for granted (Bonney, (2013). Some stakeholders in the beneficiary communities complain about the poor nutritive value of the meals when caterers attempt to pre-finance the meals preparation. This is evidenced in the research study by Lynch (2013). Eventually, the academic performance of the beneficiaries will not be enhanced through the GSFP programme as envisaged.

A Ghanaian newspaper publication, reported that caterers under the GSFP programme are not paid readily, sometimes the payment accumulations in arrears of six months before payments are made. The publication further revealed that the lack of funds for the programme has compelled some caterers to feed the beneficiaries twice or thrice per week as against the five times arrangement for a week (Bonney, 2013). This raises concern because the programme is a national programme being funded with support of other development partners. This situation presents a problem that can be argued to be undermining the programme.

As far as the implementation of the GSFP in the KEEA Municipality is concerned, empirical evidence available suggests that the process is being controlled principally by top personnel of the Municipal Education Directorate and the Municipal Assembly. The research findings from Lynch, (2013) suggest that community level committee members, the head teachers and representatives of the Parent Teacher Association despite being at a closer level to the implementation of the process of the GFSP, appear to be side lined in the process. This majorly impede any efforts to involve those at the community level in implementing the programme.

This finding from Lynch, 2013 in turn proves that local political intervention and control of the implementation of the GSFP, with regards to the KEEA Municipality, the community level participation has been encumbered by a concentration of control at the top hierarchy of the Municipal Assembly. Consequently there is loss of power and control over policy implementations strategies. Although the Government of Ghana is aimed at working to eradicate hunger, the level of commitment of the KEEA Municipality as a key actor to such a laudable initiative by the government cannot remain unquestioned. Despite this however, one 
cannot dispute the estimated figures which points to the idea that the GSFP is fast growing in terms of beneficiaries the KEEA Municipality and the Central Region as a whole.

This empirical evidence then suggest that, it is not too late for the implementing actors of the programme in the municipality to re-strategize to examining the implementation challenges of the GSFP further. More importantly, within a wider catchment area of the beneficiaries zones. As the year 2018 marked thirteen years of the inception of the GSFP in the KEEA municipality, there is a large amount of scope on which to draw conclusions from the lessons learned. These conclusions would serve as the foundation in constructing strategies for improving the future development of the programme at large.

Furthermore, evidence shows that a system needs to be established, delineating the specific roles of all key actors for the programme implementation in the Municipality especially at the community level. This would ensure that community actors of the programme such as teachers, caterers, local committee members, the Parent Teacher Association and School Management Committee would be encouraged to give off their best to support the programme in the Municipality.

\section{THE CHALLENGES OF THE SCHOOL FEEDING}

\section{Programme in KEEA Municipality}

The introduction of the school feeding programme in the KEEA Municipality has made some successes. Despite the successes, the GSFP like many of programmes of its kind is bedeviled with some challenges nationally and in the KEEA Municipality. These challenges tend to have diverse effects on the programme, actors as well as the beneficiaries of the programme.

Some of the challenges that the programme face in the KEEA municipality include: a policy guideline, funding, community involvement, capacity of staff, linkage with agriculture logistics and other supplies and monitoring and evaluation.

The GSFP since its inception has been without a policy guideline, some proponents of the programme believe this has been a major problem for programme implementation. The GFSP is consistent with major development policies and strategies of the government of Ghana, yet there is no clear government policy or legislature that guarantees its status (Kedze, 2013). Considering the wide coverage of the programme and its linkages with various sectors especially education, health and agriculture, it is prudent that a policy direction backed by legislation is established. This can go a long way to enhance the activities of the programme and guarantee its status. (GSFP AOP, 2011). Although it is still not clear how far plans are advanced for the development of a policy and also if the policy has been developed, how far it is from being adopted and approved. Thus the GFSP is truly worthy of its accredited status as a laudable strategic programme for the vulnerable children in the KEEA Municipality and its communities and for that matter Ghana.

The government of Ghana has demonstrated greater commitment to fund the GFSP through the national budget to ensure the sustainability of the programme. However, the initial agreement with donor support from the Dutch government elapsed in 2010. Since then, the burden of funding the GSFP now rest heavily on the government of Ghana. Sometimes, the government finds it difficult to secure money for the timely and regular release to the Municipal Assembly and to the beneficiary schools. When this happens the Municipal Assembly is unable to pay caterers who provide food for the beneficiaries. Originally, the GSFP was designed in such a way that the School Implementation Committee (SIC), made up of locals actors, could work alongside with local farmers to ensure direct procurement of food commodities from the local 
farmers (Morgan\&Sonnino, 2008). This arrangement has been compromised in the municipality with introduction of the supplier and the caterer models thus limiting the goal of creating markets for the local farmers.

The supplier model whereby private suppliers food commodities are procured outside school communities denies local farmers access to direct market of their farm produce to the GSFP. Secondary, the supplier model does not respect the role of the local communities as they are not part of the decision making process with regards to the foods to be purchased and from which part of the country (Morgan\&Sonnino, 2008). The major setback of the caterer model of procurement with the GSFP is that urban and per-urban communities in the municipality caterers tend to buy more imported food commodities. A small portion or no food commodity is purchased from the local farmers in the school communities (Sulemana et al., 2013; Hauware, 2008). All these challenges with regards to the procurement with the GSFP in the Municipality tend to defeat the objective of the programme of using locally-grown foodstuffs with the view to creating market for the local farmers in the school communities.

The GSFP in the KEEA Municipality has increased enrollment, participation and retention of school children in beneficiary school communities. Most of the beneficiary schools in the municipality have increased their enrolment more than the national average quota for the beneficiary schools could accommodate. Despite the increase in the enrolment in the schools, there has not been any corresponding expansion in terms of infrastructure and other logistical supplies and even the supply of food commodities. Therefore, there is pressure on the available scares resources of the beneficiary schools. The result of this challenge is that there is overcrowding in the classrooms thus limiting the quality of teaching time especially where teachers are engaged in the supervision during meal times.

Ideally, it is envisaged that such factors as adequate trained teachers, learning materials, and physical facilities should be provided to meet the demands of the increased enrolments in the schools to promote teaching and learning; however, if these resources are not provided to support the GSFP in the beneficiary schools in the communities, the academic performance of the pupils is not very likely to improve. It therefore follows that the impact of the increases in the enrolments on the academic performance of GSFP beneficiary schools pupils in the KEEA Municipality is mixed and much depends on prevailing conditions of a particular GSFP community or beneficiary school.

Empirical evidence from research studies in the KEEA Municipality (Lynch, 2013) suggest that, the GSFP has been implemented in a manner that key stakeholders at the Municipal, district and district levels were not prepared adequately to take up their respective roles at the initial stages of programme implementation. The GSFP was expected to have sensitized and educated the key stakeholders enough to explain to them the objectives of the programme, the guidelines for the implementation as well as their respective roles. This is a missing link of the programme planning and its implementation. The effect of this challenge is that, the key stakeholders of the programme in the implementation have little or no understanding at all of the implementation processes and their expected roles.

There appears to be the lack of team spirit and rapport among the stakeholders of the GSFP at the municipal, district and school levels. There a number of schools in the KEEA municipality without effective and active School Implementation Committee (SIC) (Bulhl, 2012; Sulemana, 2013) Community level actors such as parents, locals chiefs and other actors do not perform their respective roles in the day- to- day activities of the programme. Amy, (2013) corroborates this assertion by indicating that in the KEEA Municipality, the municipal Chief 
Executives and some head teachers take unilateral decisions to make sure that beneficiaries are provided with meals

The lack of infrastructure and other logistical support in the beneficiary schools such as kitchens, store rooms, dining halls, serving plates, cups, spoons and good sources of portable water among others aggravate the plight of the GSFP in the KEEA municipality. Many schools in the municipality do not have good kitchens for food preparation and meal services. This problem is not peculiar only to the GSFP in the KEEA municipality as a study conducted in 2009 by Ghana Dot in 21 beneficiary districts in the country reported that about $61 \%$ of GSFP beneficiary schools lack well equipped kitchens and other cooking facilities. Sulemana et al (2013) also reported that many schools of the GFSP prepare food under trees and when it is raining, the food preparation is done in the classrooms or the corridors of the classrooms. This has a negative effect on the hygienic environment needed for food preparation to protect the overall health status of the beneficiaries as well as teaching and learning. Again, because beneficiary schools lack dining halls where meals are served, pupils use their classrooms as dining rooms. This is quite disturbing as pupils soils their books and also make the classrooms untidy for academic work. Oduro-Ofori et al (2014) indicated that this hampers good teaching and learning and also poses serious health threats for the children.

In beneficiary schools of the GSFP where there is lack of good sources of water, pupils sometimes had to sacrifice their instructional time to look for portable water for drinking and for food preparation. This may impact negatively on instructional time over time, as lunch breaks are extended. The academic performance of the pupils could be affected. To argument this challenge, most of the schools have been provided with water tanks to store water. Unfortunately, most of these water tanks are not being used because of lack of connection to sources of water. Where rain water is harvested the water tanks for storage are not cleaned periodically and the water is sometime contaminated and invested with mosquito larvae. Thus rendering the water unsafe for the children's consumption.

Cooks employed on the GSFP in the KEEA municipality are normally untrained on food and nutrition, kitchen hygiene and environmental sanitation. The majority of the cooks do not have health certificates. They also do not receive any on- the- job training to enhance their work. Again the introduction of the caterer model of food procurement makes it difficult to thoroughly check on meals prepared for the children outside the school environments. This model operates mainly in urban communities within the municipality as most key actors fail to play their roles in the GSFP in these communities. Under the model, there is an agreement between the Municipal Assembly and the Caterers in terms the menus for food preparation, however, there is minimal participation of the beneficiary schools and the local actors by this agreement. In this regard, it becomes difficult to monitor the caterers on the quality, quantity and the safety of the meals for prepared for the beneficiaries.

Finally, GSFP beneficiary schools in the municipality do not have sanitary facilities (Ghana Dot, 2009 ) reported that between $26 \%$ and $35 \%$ of GSFP beneficiary schools do not have access to wash rooms ; almost $87 \%$ of the schools do not have hand washing facilities(Veronica buckets). The situation poses a very serious health threat to the beneficiaries, considering how the children come into contact with the poor sanitary environments and eat with unclean hands. 


\section{SUGGESTIONS/RECOMMENDATIONS TO \\ Improvement GSFP in the KEEA \\ Municipality}

Based on the issues and challenges highlighted in this study that may limit the effectiveness of the GSFP in the KEEA municipality, the following suggestions and recommendations are offered to strengthen to the programme in the municipality. This is important as the programme concerns vulnerable groups of the Ghanaian society, and to achieve its long term goal, it would be most prudent to adopt strategies to curb the lapses and loopholes that militate against programme success.

1. The GSFP since its inception is without policy guidelines for which some proponents claim as the major cause of the challenges militating against the effective implementation of the programme. It is therefore very prudent for the Government of Ghana to come out with clear policy directions, backed by legislation to enhance the day- to- day activities of the programme in the beneficiary communities in the municipality.

2. To help resolved the problem of funding the programme generally and in the KEEA municipality, as suggested by HGSP TAP document(2011), there should be the possibility of developing a resource mobilization plan at national, regional, municipal and district levels to help guarantee the sustainability of the programme beyond government funding. This plan should be informed by research on the opportunities and benefits from the private sector and the Ghanaian Diaspora participation. The plan should also include a strategy to secure CSOs, NGOs and school communities' involvement in the GFSP.

3. The current caterer model of the GSFP in the KEEA municipality is unable to link farmers in the school communities with caterers for the supply of food commodities needed for the programme. Thus it is important to establish the linkage between local farmers in the communities and the programme objectives to support the local farmers to market their farm produce for the GSFP.

4. The GFSP should be redesigned with strengthened emphasis to formally include other stakeholders of school communities in the municipality to assist in the implementation and to own the programme for its sustainability. School communities benefiting from the programme could be educated on their roles and responsibilities to enhance effective programme management and accountability.

5. For effective local monitoring and evaluation practices to support the tracking and execution of the GSFP in the municipality, coordinators and monitors require adequate logistical support for their work.

6. Regular provision of portable water by the Municipal Assembly to the beneficiary schools is needed. This could help ease access to the supply of portable water to beneficiaries and improve hygiene and sanitation in the school environments.

7. As far as the management of the GSFP in the KEEA municipality is concerned, evidence provided in this study suggests that the programme is principally controlled by top personnel of the Municipal Assembly and the Education Directorate, sliding other committee members. This situation impede any efforts to involve those at the community level who are the local actors in the implementation process of the GSFP. A system needs to be established to indicate who exactly controls the day- to- day activities of the programme in the Municipality.

\section{CONCLUSION}

This paper sought to examine the issues and challenges associated with the management of the GSFP in the KEEA municipality. The evidence provided by this paper indeed points to the conclusion that the GSFP has so far helped to improve enrollment, participation and retention 
of primary school children in the municipality. This evidence corroborates with the main philosophy of the GSFP. Evidence of such growth and expansion is commendable and must be sustained. However, attention must be paid in augmenting the challenges of the programme implementation in the beneficiary communities, in order to achieve the long term lofty goals enshrined the programme planning document, since it concerns the vulnerable groups in the country.

\section{References}

Abotsi, A. K (2013) 'Expectations of School Feeding Programme: Impact on School enrolment, Attendance and Academic Performance in Elementary Ghanaian Schools'. British Journal of Education, Society \& Behavioral Science, 3 (1): 76-92, 2013.

ABU-Bakar, S.Y. (2008). A study of the Ghana school feeding program: A tool for poverty reduction or for widening social inequalities? Retrieved from www. gnecc.org/.../A $\% 20$ study $\% 20$ of $\% 20$ the $\% 20$ GSFP $\% 20$ current.p

Adamu-Issah, M., Elden, L., Forson, M., \&Schreyer, T. (2007). Achieving universal primary education in Ghana by 2015: A reality or dream? United Nations Children's Fund (UNICEF), NY: New York. Retrieved from www.theghanaianjournal.com/.../acheiing-universal-priamry-educat...

Afoakwa, E.O. (n.d). Home grown school feeding program- the Ghanaian mode as icon for Africa. Retrieved from http//www.genf.org/library/Ghana-School-Feeding-Programme-Overview-and-Progress.pdf

Akanbi A., Ayobami J., Ofoegbu S., \&Onyema F. (2013). Impact of Perceived Organizational Commitment of a food and Beverage Firm in Nigeria. International Journal of Humanities and Social Science Vol.3 No 14.

Alhassan, A., \& Alhassan F. (2014). An assessment of the operational challenge of the Ghana school, feeding program. The International Journal of Business \& Management, 2 (8) 154-173.

Amy, (2013) Inaction or In Action', The Effectiveness of the School Feeding Programme: The Case of Ntranoa School. KEEA, Ghana. Unpublished Post graduate Dissertation, University of Limerick. Ollscoil Limerick.

Ankomah, A. Y, J.A Koomson, R.S. Bosu and G.K.T Oduro (2005) 'a review On the Concept of Quality in Education: Perspectives from Ghana'. EdQual Working Paper No. 1

Buhl, A. (2012). Meeting the nutritional needs through school feeding: A snapshot of our African nations. Washington: University of Washington. Retrieved from www.gcnf.org/.../Meeting-NutritionalNeedsThroughSchool-Feedin...

Bukari, M., \& Hajara, I.P.N (2015). The Ghana school feeding program: Factors affecting enrolment of pupils in Garu-Temapne District, Upper east Region. International Journal of Innovative Research and Development, 4 (1), 298-303

Confed Ghana (2012). What works in girls' education in Ghana: A critical review of the

Del Rosso, J.M. (1999). School feeding program: improving effectiveness and increasing the benefit to Education. Oxford: partnership for Child Development.

ECASARD/SNV Ghana (2009). Ghana school feeding program (GSFP) initiative and the farmers dream: a survey on the role of farmer based organizations (FBOs) in the implementation of Ghana School Feeding Program (GSFP) in the Greater Accra Region. Retrieved from www.snvworld.org/.../ghana/.../ECASARD\%20Agric.

Education for All Global Report (2012) 'Youth and skills: Putting education o work. UNESCO publishing.

Government of Ghana (2011) 'Home Grown School Feeding Technical Assistance Plan'.

Government of Ghana (2011) 'The Ghana School Feeding Programme Annual Operating Plan'. Government of Ghana.

Hauwere, K., D. (2008). Ghana school feeding program: A practical exploration of the 'behind the façade' approach. Retrieved from www.snvworl.org/en/.../ghana/GSFP;A\%20practical\%20 explorti...

Kedze, S (2013) The Distortive Effects of Ghana's School Feeding Programme on Primary Education Delivery: The Case of Adentan. Municipality. Unpublished Masters Dissertation. The Hague, Netherlands.

m.peacefmoline.com/pages/local/news/2018/357978php.

Morgan, K., \& Sonnino, R. (2008). The school food revolution: public food and the challenge of sustainable development. London: Earths can. 
Oduro-Ofori, E, Adwoa-Yeboah, G. (2014). The contribution of the Ghana school feeding program to basic school participation: A study of selected schools in Kwaebirem district of Ghana. Developing Country Studies, 4 (19), 4050 .

Oppong-Mensah, K. (2009). The contribution of distance education in meeting the challenged in teacher education in Africa: The Ghanaian experience. Retrieved from www.deta.up.ac.2a/presentations/ word/okpong\%20Mensah.pdf

Sulemana, M., Ngah, I., 7 Majid, M.R (2013): The challenges and prospects of the school feeding program in northern Ghana. Development in Practice, 23 (3), 422-432.

Tomlinson, M (2007) 'School feeding in east and southern Africa: improving food sovereignty or photo opportunity?' Equinet Discussion Paper Number 46.

Uduku,0,(2011) 'School building 'School building design for feeding programmes and community: insights from Ghana and South Africa' in International Journal of Educational Development., 31, 59-66.

UNESCO (2000). Informe Final, Foro Mundial Sobre la Educacion, Dakar, Senegal.

World Bank (2004). School Fees: A Roadblock to Education for All. Education, the World Bank.

World Food Program (2007a). "Food for Education Works: A review of WFP FFE program monitoring and evaluation 2002-2006." School Feeding Unit, WFP Rome.

World Food Program (2009). Feed minds, change lives - school feeding: Highlights and new direction. Retrieved from home.wfp.org/.../newsroom/wfp204709.pdf 